\title{
El empresario: factor clave del desarrollo económico
}

Alfonso Delgadillo Parra. *

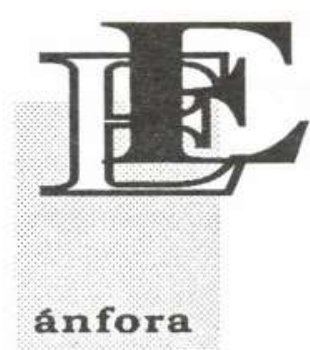

insuficiente de toda clase de bienes manufacturados. Es ahí en donde entran en juego las ideas, los conocimientos y las acciones de las personas responsables de la dirección y la aplicación de la inversiones, de los generadores del mejoramiento y el desarrollo tecnológico, y de los investigadores científicos.

Y no es que necesariamente suceda, como muchos piensan, que la invención o el descubrimiento de nuevos productos cree, con la ayuda de toda la parafernalia de la publicidad y el mercado, nuevas necesidades a las gentes. No siempre es así. Al contrario, como lo dice Schumpeter, «la producción sigue a la necesidad: va, por decirlo así, a rastras de ella» Lo que ocurre es que la competencia entre productores obliga a innovar y a desarrollar productos nuevos para captar a los consumidores, so pena de quedarse atrás, barridos por un mercado impersonal, y como tal, ajeno a la compasión y a toda clase de sentimientos.

Es entonces al empresario moderno a quien corresponde accionar como responsable de la permanencia y el desarrollo de la empresa y del aumento de las utilidades. A él le compete la dirección de los procesos de búsqueda de los recursos, conducentes a la reducción de los costos o al mejoramiento de sus mercancías, la definición de nuevas líneas de productos que llenen necesidades reales o latentes, y la conquista de mercados seguros para su renovada producción. Sólo con estas acciones el empresario puede garantizar el cumplimiento de las tres responsabilidades antes enunciadas. Y con ellas está garantizando, sin proponérselo como objetivo, cual nueva mano invisible, el avance de la ciencia y de la tecnología. 
Con toda seguridad, pensadores como Juan Bautista Say, (1767-1852), el Conde de Saint Simon, (1760-1825), y Joseph Schumpeter, (1883-1950), tuvieron en mente similares principios fundamentales cuando aludieron en sus teorías a la importancia definitiva del industrial y el empresario en el desarrollo de la economía.

El economista francés Juan Bautista Say tuvo el acierto de distinguir entre el empresario y el capitalista, hecho que no habían logrado lumbreras del liberalismo económico como Adam Smith y David Ricardo, para quienes el que aporta el capital y el que dirige los procesos de producción son una misma persona. Para Say el capitalista es el aportador del capital y a quien se asegura el pago de una cantidad determinada (interés) por el servicio que su capital presta a la producción. En cambio, el empresario es el que compra servicios productivos a precios ciertos para transformarlos en artículos nuevos que tendrá que vender en un mercado incierto en cuanto a la cantidad y al precio. Su retribución es la diferencia que haya logrado alcanzar entre los ingresos obtenidos en el mercado y los costos en que incurrió al comprar los servicios productivos. Por eso al empresario, al combinar los factores o "servicios productivos» corresponde el papel principal en la producción. Así lo expresa Say: «Les haré notar que el empresario industrial es el agente principal de la producción. Las otras operaciones son ciertamente necesarias para la creación de productos: pero es el empresario el que las combina, el que les da un impulso útil, el que las convierte en valores. El juzga de las necesidades y sobre todo de los medios para satisfacerlas. El compara el objetivo con los medios. Por ese motivo su calidad principal es la del discernimiento. personalmente puede carecer de ciencia, siempre y cuando haga un empleo juicioso de la de los demás. Puede no trabajar con sus propias manos, sino servirse de las de otras personas,. pero no puede dejar de usar su propio juicio. Porque entonces podría producir con gran gasto aquello que carece de valor.» ${ }^{1}$

Para el Conde Saint Simon, quien renunció al título nobiliario para actuar sin lastres ni compromisos en la Revolución Francesa, el mundo descansa en la industria, la cual es fuente de riqueza y de libertad. Los industriales, basándose en la ciencia, son los que deben gobernar la sociedad, buscando el bienestar de todos los asociados. «Una nación no es más que una gran sociedad industrial», dirá el importante socialista utópico, y agregará que el progreso de la sociedad es constante y se manifiesta a través de la industrialización, por lo cual la dirección de la sociedad debe estar en manos de los industriales." 2

Ya en este siglo es el economista austriaco Joseph Schumpeter, catedrático en Bonn y en Harvard, quien asume con fuerza dialéctica indiscutible el señalamiento de la importancia de los empresarios en el desenvolvimiento económico. Para empezar, Schumpeter diferencia entre trabajo director y trabajo dirigido, indicando que lo que diferencia el uno del otro, es que el
1. GONNARD, René. Historia de las Doctrinas Económicas. Aguilar, 1950

2. SCHUMPETER, Joseph. El desenvolvimiento Económico. Fondo de Cultura Económica, 1956 

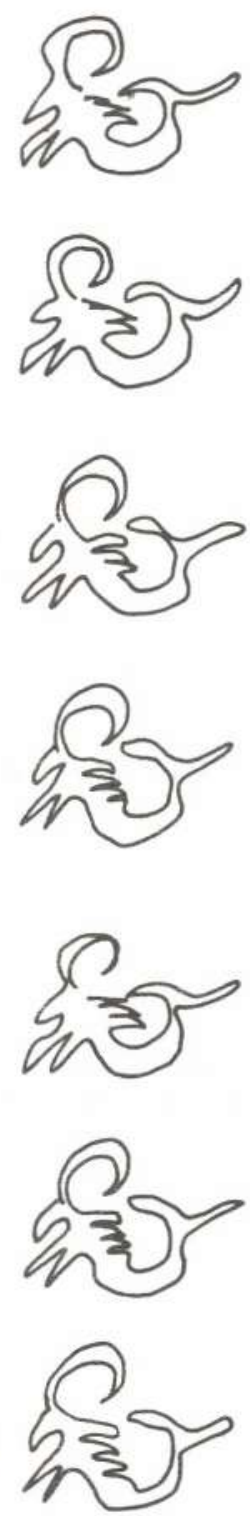

trabajo director se halla más alto en la jerarquía del organismo productivo, mientras el trabajo ejecutor se halla al mismo nivel bajo de los demás factores, como la tierra, y con la misma función de ésta, desde el punto de vista económico. El trabajo del director ocupa una posición preeminente respecto al ejecutor o dirigido y al uso de los demás recursos, constituyendo un tercer factor productivo. Tiene algo de creador, en el sentido de que establece sus propios fines». Si homologamos el trabajo del director con el trabajo del empresario, vemos cómo Schumpeter le está dando a éste el carácter de «nuevo factor productivo» (además de los factores clásicos de la tierra, el capital y el trabajo) y le está reconociendo su carácter de «creador», porque es capaz de determinar sus propios objetivos, rasgo que no poseen los restantes factores, y lo que le da realmente su posición de preeminencia sobre ellos.

Para Schumpeter «producir significa combinar materiales y fuerzas que se hallan a nuestro alcance. Producir otras cosas o las mismas por métodos distintos, significa combinar en forma diferente dichos materiales y fuerzas... El desenvolvimiento, en nuestro caso, se define por la puesta en práctica de nuevas combinaciones: Emprender una «empresa» es empezar a realizar esas nuevas combinaciones, y los individuos encargados de dirigir esa realización son los empresarios. Pero, insiste el eminente profesor, solamente se es empresario cuando se llevan efectivamente a la práctica nuevas combinaciones. Yel concepto de nuevas combinaciones cubre los siguientes casos: a. La introducción de un nuevo bien o producto. b. La introducción de un nuevo método de producción. c. La apertura de un nuevo mercado. d. La conquista de una nueva fuente de aprovisionamiento de materias primas. Y e. La creación de una nueva organización de cualquier industria.

De todo lo anterior puede concluirse que el empresario juega un papel estratégico en el desarrollo económico sin importar sus motivaciones personales, así sea la simple ganacia pecuniaria, porque ésa y todas las demás posibles, convierten al empresario en un motor del progreso industrial que conduce al desenvolvimiento de la economía. Además, no podemos olvidar que... «sin desenvolvimiento no hay ganancia, y sin ésta no hay desenvolvimiento... porque en el sistema capitalista sin ganancia no habrá acumulación de riqueza», como lo afirma nuestro citado autor.

En consecuencia, es inmensa la responsabilidad que cabe a los empresarios industriales, agrícolas, ganaderos, comerciales, financieros, y, en fin, generadores de toda clase de bienes y servicios, porque en ellos está, o debe estar, la capacidad de crear nuevas empresas, de incrementar la producción general, de abrir nuevas oportunidades de ocupación y empleo para todos los recursos, de fomentar el comercio internacional y, finalmente, de facilitar las condiciones que representan el mejoramiento de la calidad de vida de un pueblo. 
A los empresarios, mancomunadamente con la clase dirigente y en forma concertada, corresponde también determinar el rumbo que ha de tomar la economía y señalar las metas y los objetivos que en conjunto constituyen los grandes propósitos nacionales y que deben ser como el faro que guía el desenvolvimiento del país.

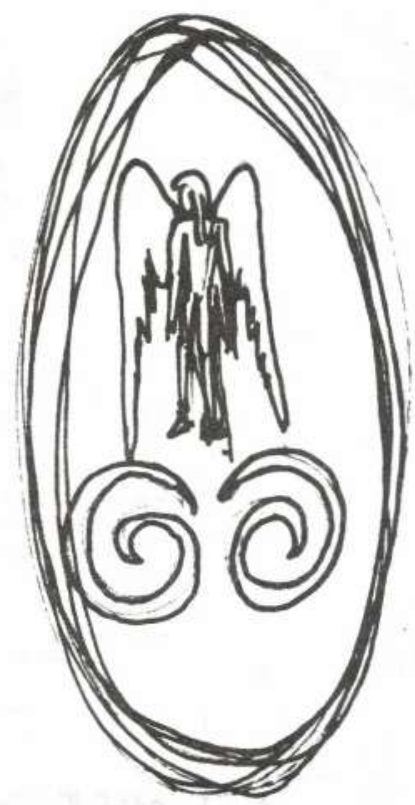

